\title{
Germinação de sementes de Emilia coccinea (Sims) G. DON em função da luminosidade, temperatura, armazenamento e profundidade de semeadura
}

\section{Germination of Emilia coccinea (Sims) G. DON as a function of light, temperature, storage and sowing depth}

\author{
Bruno França da Trindade Lessa ${ }^{1 *}$; Vilma Marques Ferreira ${ }^{2}$; \\ João Correia de Araújo Neto ${ }^{3}$; Renan Cantalice de Souza ${ }^{4}$
}

\section{Resumo}

\begin{abstract}
Emilia coccinea (Sims) G. Don (Asteraceae) é uma espécie daninha bastante frequente nas lavouras brasileiras, sendo também considerada hortícula por apresentar propriedades medicinais. O estudo da sua germinação pode contribuir para o seu manejo em áreas onde é indesejada, ao tempo que pode auxiliar a sua produção em hortas medicinais. O objetivo deste trabalho foi estudar, em três ensaios, o comportamento germinativo de sementes de E. coccinea em função da luz, temperatura, armazenamento e profundidade de semeadura. No primeiro ensaio os aquênios (frutos-semente) foram submetidos a diferentes temperaturas $\left(10,20,30,40\right.$ e $\left.20-30^{\circ} \mathrm{C}\right)$ e qualidades de luz (branca, vermelha, vermelhodistante e escuro), no segundo, os aquênios recém-colhidos e armazenados por 3, 6, 9 e 12 meses foram submetidos às mesmas qualidades de luz citadas anteriormente e incubados à $30^{\circ} \mathrm{C}$, para $\mathrm{o}$ terceiro ensaio os aquênios foram semeados em substrato areia + solo em diferentes profundidades $(0$, $1,2,3$ e $4 \mathrm{~cm}$ ). O delineamento experimental em todos os ensaios foi inteiramente casualizado com quatro repetições de 50 sementes, nos quais avaliou-se a porcentagem e velocidade de germinação e emergência de plântulas. A germinação de E. coccinea é maximizada sob a temperatura constante de $30^{\circ} \mathrm{C}$ ou alternada de $20-30^{\circ} \mathrm{C}$, sob a luz branca. Aos nove meses de armazenamento, os aquênios perdem completamente a fotodormência. A capacidade de emergência das plântulas é superior quando as sementes encontram-se na superfície do substrato.
\end{abstract}

Palavras-chave: Espécie daninha, aquênios, qualidades de luz, emergência de plântulas

\begin{abstract}
Emilia coccinea (Sims) G. Don (Asteraceae) is a weed species quite frequently in the Brazilian farming, is also considered horticultural plant for having medicinal properties. The study of their germination can contribute to their management in areas where it is unwanted, also can help their production in medicinal gardens. The objective this work was to study, in three trials, the germination of E. coccinea as a function of temperature, light, storage and sowing depth. In the first test, the fruits-seed had been submitted at different temperatures $\left(10,20,30,40\right.$ and $\left.20-30^{\circ} \mathrm{C}\right)$ and light qualities (white, red, far red and dark), in the second, the newly harvested and stored fruits-seed (3, 6, 9 and 12 months) had been submitted at same light qualities listed above and incubated in camera at $30^{\circ} \mathrm{C}$. For the third test the

\footnotetext{
${ }^{1}$ Discente do Curso de Doutorado em Agronomia/Fitotecnia, Centro de Ciência Agrárias, CCA, Universidade Federal do Ceará, UFC, Campus do Pici, Fortaleza, CE. E-mail: brunoftl@yahoo.com.br

2 Prof ${ }^{\mathrm{a}}$. Associado 1, Centro de Ciência Agrárias, CECA, Universidade Federal de Alagoas, UFAL, Rio-Largo, AL. E-mail: vmarques_ferreira@hotmail.com

3 Prof. Adjunto, UFAL, Rio-Largo, AL. E-mail: jcanetto2@hotmail.com

${ }^{4}$ Bolsista de Pós-Doutorado, UFAL, Rio-Largo, AL. E-mail: renanibp@hotmail.com

* Autor para correspondência
} 
fruits-seed had been seeded in sand+soil under different depths $(0,1,2,3$ and $4 \mathrm{~cm})$. The experimental design in all trials was completely randomized with four replications of 50 seeds, where evaluated the percentage and speed of germination and seedling emergence. The germination of E. coccinea is maximized under the temperature of 30 or $20-30^{\circ} \mathrm{C}$, under white light. With nine months of storage the fruits-seeds lost completely the far red and dark light sensibility. The seedling emergence is greater when the seeds are at the substrate surface.

Key words: Weed species, fruits-seed, light qualities, seedling emergence

\section{Introdução}

Conhecida popularmente como pincel-deestudante ou serralhinha, Emilia coccinea (Sims) G. Don (Asteraceae) é uma planta considerada daninha, nativa da Ásia, Polinésia, África e América, sendo nesta última muito comum, infestando frequentemente lavouras anuais e perenes, e notadamente presente em quase todo território brasileiro (LORENZI, 2006). Por isso apresenta grande expressão econômica, uma vez que a presença de plantas indesejáveis em áreas de cultivo acarreta competição principalmente pela extração de nutrientes e água, podendo ainda exercer inibição química (alelopatia) sobre o desenvolvimento das plantas, proporcionando perdas de produção às culturas agrícolas no Brasil em torno de 20 a $30 \%$ (LORENZI, 2008).

Por outro lado, esta espécie também é citada na literatura como medicinal, pois avaliações químicas de amostras desta planta identificaram a presença de alcalóides e taninos, promovendo atividades antimicrobianas e antidiarréicas (TEKE et al., 2007). No Nordeste brasileiro, a infusão de suas folhas é usada contra febres e diarréias (AGRA et al., 2008), mas também há relatos de indicação desta técnica para amenizar cólicas e inflamações nos olhos (NOUMI; DIBAKTO, 2000).

O estudo de plantas medicinais, no enfoque agronômico é uma realidade recente. Informações técnicas ainda são escassas quando se tem por objetivo a sua produção em escala (CORRÊIA JÚNIOR; SCHEFFER; MING, 2006). Estudos sobre a germinação de sementes podem trazer contribuição no sentido de otimizar a propagação destas espécies, evitando prejuízos decorrentes de falhas na emergência, ou formação de plântulas de menor vigor.

Tanto para entender o processo de infestação desta espécie em áreas de cultivo, quanto para difundir sua utilização para fins medicinais, o estudo da germinação de sementes torna-se indispensável. Roberts (1999) relata que o processo de infestação da maioria das plantas daninhas depende diretamente da germinação de suas sementes, que por sua vez, é influenciada por fatores ambientais e/ou internos à mesma, onde cada fator pode atuar de forma isolada ou em interação com os demais (NASSIF; VIEIRA; FERNANDES, 1998).

Dentre os fatores ambientais de maior influência na germinação está a temperatura, que tanto pode agir sobre a velocidade de absorção de água, como também sobre as reações bioquímicas que desencadeiam o processo (CARVALHO; NAKAGAWA, 2012). Três pontos críticos são identificados notocanteà temperatura de germinação, conceituados como temperaturas cardeais, que são as temperaturas: máxima - acima da qual não há germinação devido à desnaturação das enzimas; mínima - abaixo da qual não há germinação em tempo razoável, pela falta de energia de ativação para o sistema enzimático; e ótima - aquela que resulta no maior número de sementes germinadas em menor tempo (FLOSS, 2008).

Outro fator que pode ter influência direta no processo germinativo é a luz, que está associada a um mecanismo de dormência caracterizado pelo controle do equilíbrio entre substâncias promotoras e inibidoras de crescimento, sendo este equilíbrio condicionado pelo comprimento de onda que incide sobre a semente, alterando a forma do fitocromo 
(pigmento receptor de luz) presente na mesma, fenômeno denominado fotorreversibilidade do fitocromo (KENDRICK; FRANKLAND, 1981). Já é conhecida a existência de cinco diferentes tipos de fitocromo, phy A, phy B, phy C, phy D e phy $\mathrm{E}$, sendo os dois primeiros os mais atuantes na germinação de sementes (CARDOSO, 2008). Segundo Floss (2008) as sementes podem ser classificadas em fotoblásticas positivas, que germinam melhor na presença de luz, fotoblásticas negativas, que germinam melhor na ausência de luz e fotoblásticas neutras, que germinam tanto na presença quanto na ausência de luz. A resposta da germinação à qualidade da luz não é caractere absoluto, dependendo de inúmeros fatores, tais como estádio de maturação, tempo de armazenamento, integridade do tegumento, potencial hídrico do meio e temperatura (CARDOSO, 2008; VIVIAN et al., 2008).

Um ponto chave na dinâmica de regeneração das espécies invasoras é o posicionamento das sementes ao longo do perfil do solo, assim a avaliação da taxa de emergência no tocante a profundidade de semeadura pode gerar respostas para determinar a habilidade das espécies, imediatamente após a germinação, de superar as barreiras físicas ao longo do desenvolvimento da plântula (DIAS-FILHO, 1998), além de viabilizar técnicas de semeadura quando o objetivo é a produção de E. coccinea em hortas medicinais.

O objetivo do presente trabalho foi conhecer o comportamento germinativo de sementes recém-colhidas de Emilia coccinea sob diferentes temperaturas e qualidades de luz, além de avaliar o efeito do armazenamento dos aquênios na fotossensibilidade da germinação e, por fim, conhecer a capacidade de emergência das plântulas em função de diferentes profundidades de semeadura.

\section{Material e Métodos}

\section{Local de execução}

Para os estudos da germinação de sementes e emergência de plântulas de E. coccinea, aquênios (fruto-semente) da espécie foram colhidos manualmente de inflorescências completamente expandidas em infestações naturais de áreas cultivadas e terrenos baldios do município de Coruripe - AL. Os experimentos foram realizados no Laboratório de Análise de Sementes do Centro de Ciências Agrárias da Universidade Federal de Alagoas.

Ensaio 1: temperatura e qualidade de luz

Aquênios recém-colhidos de $E$. coccinea foram submetidos à assepsia com imersão em álcool (70\%) por um minuto, em seguida foram colocados no interior de caixas plásticas transparentes ("gerbox"), de dimensões $11,0 \times 11,0 \times 3,5 \mathrm{~cm}$, tendo papel de filtro como substrato, previamente umedecido com água destilada, sendo o conteúdo de água equivalente a 2,5 vezes a massa do substrato.

Os gerboxes, contendo os aquênios, foram acondicionados em germinadores de câmara vertical tipo B.O.D. (Biochemical Oxygen Demand) regulados às temperaturas constantes de 10,20 , 30 e $40^{\circ} \mathrm{C}$ e alternada de $20-30^{\circ} \mathrm{C}$ (12 horas para cada) com luz branca contínua, esta obtida por meio de quatro lâmpadas fluorescentes de 20 w cada, e fotoperíodo de 12 horas.

As qualidades de luz testadas foram: branca, vermelha, vermelho-distante e escuro. Aluz vermelha foi obtida envolvendo as caixas transparentes em duas folhas vermelhas de papel celofane, e para o vermelho-distante duas folhas vermelhas e duas azuis, do mesmo papel, conforme indicações de Almeida e Mundstock (2001), enquanto o escuro foi obtido utilizando-se gerbox preto. 
Ensaio 2: armazenamento e qualidade de luz

Os aquênios foram armazenados em câmara seca com temperatura de $23^{\circ} \mathrm{C} \pm 4^{\circ} \mathrm{C}$ e umidade relativa do ar de $45 \%$, dentro de sacos de papel tipo "Kraft" com realização a cada três meses de testes de germinação, realizado igualmente ao ensaio um, em câmara B.O.D. regulada a temperatura de $30{ }^{\circ} \mathrm{C}$ sob as luzes branca, vermelha, vermelhodistante e escuro. Este ensaio se estendeu por 12 meses, totalizando cinco diferentes períodos de armazenamento incluindo o controle ( $(0,3,6,9$ e 12 meses).

Ensaio 3: profundidade de semeadura

Aquênios recém-colhidos foram postos em bandejas plásticas $(29,0 \times 22,0 \times 7,0 \mathrm{~cm})$ contendo areia lavada e solo, este último coletado na camada de $0-20 \mathrm{~cm}$ em Latossolo Amarelo coeso distrófico (EMBRAPA, 2006), na proporção de 1:1, mistura previamente esterilizada em estufa a $105^{\circ} \mathrm{C}$ por 24 horas, as quais foram mantidas em ambiente de laboratório (temperatura média de $26,9^{\circ} \mathrm{C}$ e umidade relativa média do ar de $74 \%$ ), sendo a semeadura realizada às profundidades de 0 (superfície), 1, 2, 3 e $4 \mathrm{~cm}$.

\section{Variáveis analisadas}

Para todos os ensaios, a contagem da germinação ou da emergência de plântulas foi realizada diariamente, durante 21 dias, sendo consideradas germinadas as sementes que originaram plântulas normais, com raiz primária e parte aérea visíveis, e emergidas aquelas com o primeiro par de folhas expostos. No final de cada ensaio, foram calculados a porcentagem final e o índice de velocidade de germinação e de emergência pela fórmula proposta por Maguire (1962).

Para os tratamentos com luzes na faixa do vermelho, vermelho-distante e ausência de luz (escuro), os procedimentos de assepsia, semeadura e avaliação diária da germinação foram realizados em câmera escura, sob luz verde de segurança (20 $\mathrm{w})$.

\section{Procedimentos estatísticos}

Os ensaios foram conduzidos sob delineamento inteiramente casualizado com 4 repetições de 50 sementes e os dados submetidos à análise de variância (ANAVA) com aplicação do teste $\mathrm{F}$ a 5\% de probabilidade. O ensaio número um foi conduzido sob esquema fatorial ( $5 \times 4)$ e as médias comparadas por meio do teste de Tukey a 5\% de probabilidade; o ensaio dois sob esquema de parcelas subdivididas no tempo ( $4 \times 5)$, com as qualidades de luz constituindo as parcelas, estas comparadas pelo teste de Tukey, e os períodos de armazenamento as subparcelas com posterior análise de regressão; para o ensaio três realizou-se também análise de regressão. As análises estatísticas para os valores em porcentagem foram realizadas com os dados transformados em arc. seno $\sqrt{ } \mathrm{x} / 100$, sendo apresentados os dados originais.

\section{Resultados e Discussões}

Temperatura e qualidade de Luz

A luz branca proporcionou maiores porcentagens e velocidades de germinação na temperatura constante de $30{ }^{\circ} \mathrm{C}$ e alternada de $20-30{ }^{\circ} \mathrm{C}$, não diferindo estatisticamente entre estas $(\mathrm{p}<0,05)$ (Tabelas 1 e 2). A combinação presença de luz e temperatura de $30{ }^{\circ} \mathrm{C}$ também maximizou a germinação de sementes de outra espécie de mesmo gênero, a Emilia sonchifolia (YAMASHITA et al., 2009). Canossa et al. (2008) e Vidal et al. (2007) estudando a germinação de sementes de duas outras importantes plantas daninhas, Alternanthera tenella Colla (Amarantaceae) e Conyza bonariensis respectivamente, também verificaram otimização da germinação quando sob temperaturas na faixa de 20 a $30^{\circ} \mathrm{C}$. Essas informações permitem entender os altos níveis de infestação destas espécies nas áreas agrícolas brasileiras, principalmente na 
região Nordeste, já que esta apresenta temperatura média entre 23 e $27^{\circ} \mathrm{C}$ com altas taxas de radiação (INMET, 2013).

Para a porcentagem e velocidade de germinação (IVG) não houve diferença significativa $(p<0,05)$ entre as luzes vermelha e branca na temperatura de $20^{\circ} \mathrm{C}$ (Tabelas 1 e 2 ), e na alternada de $20-30^{\circ} \mathrm{C}$ apenas para o índice de velocidade de germinação (Tabela 2).

Tabela 1. Germinação de sementes recém-colhidas de Emilia coccinea sob diferentes temperaturas e qualidades de luz.

\begin{tabular}{|c|c|c|c|c|}
\hline \multicolumn{5}{|c|}{ GERMINAÇÃO (\%) } \\
\hline \multirow[t]{2}{*}{ Temperaturas } & \multicolumn{4}{|c|}{ Qualidades de luz } \\
\hline & Branca & Vermelha & Verm. Distante & Escuro \\
\hline $10^{\circ} \mathrm{C}$ & $0,0--$ & $0,0--$ & $0,0--$ & $0,0--$ \\
\hline $20^{\circ} \mathrm{C}$ & $41,5 \mathrm{bA}$ & $47,0 \mathrm{aA}$ & $5,7 \mathrm{aB}$ & $3,5 \mathrm{abB}$ \\
\hline $20-30^{\circ} \mathrm{C}$ & $79,5 \mathrm{aA}$ & $50,0 \mathrm{aB}$ & $0,0 \mathrm{bD}$ & $14,0 \mathrm{aC}$ \\
\hline $30^{\circ} \mathrm{C}$ & $82,0 \mathrm{aA}$ & $51,5 \mathrm{aB}$ & $1,5 \mathrm{aC}$ & $1,0 \mathrm{bC}$ \\
\hline $40^{\circ} \mathrm{C}$ & $0,0--$ & $0,0--$ & $0,0--$ & $0,0--$ \\
\hline Valor "F" p/ Temperatura & & & & $2,07^{\mathrm{ns}}$ \\
\hline Valor "F" p/ Qualidade de luz & & & & $162,46^{* *}$ \\
\hline Valor "F" p/ Interação (T x Q) & & & & $7,88^{* *}$ \\
\hline CV $(\%)$ & & & & 22,90 \\
\hline
\end{tabular}

Letras iguais (minúsculas na coluna e maiúsculas na linha) não diferem entre si pelo teste de Tukey a 5\% de probabilidade. As temperaturas de $10^{\circ} \mathrm{C}$ e $40^{\circ} \mathrm{C}$ foram excluídas da análise estatística.

** Significativo ao nível de $1 \%$ de probabilidade $(\mathrm{p}<.01)$.

ns: Não significativo ao nível de $5 \%$ de probabilidade $(\mathrm{p}<.05)$.

Fonte: Elaboração dos autores.

Tabela 2. Índice de velocidade de germinação (IVG) de sementes recém-colhidas de Emilia coccinea sob diferentes temperaturas e qualidades de luz.

\begin{tabular}{lcccc}
\hline & \multicolumn{4}{c}{ IVG } \\
\hline Temperaturas & \multicolumn{4}{c}{ Qualidades de luz } \\
\hline & Branca & Vermelha & Verm. Distante & Escuro \\
\cline { 2 - 4 } $10^{\circ} \mathrm{C}$ & $0,00--$ & $0,00--$ & $0,00--$ & $0,00--$ \\
$20^{\circ} \mathrm{C}$ & $2,22 \mathrm{bA}$ & $3,16 \mathrm{bA}$ & $0,29 \mathrm{aB}$ & $0,41 \mathrm{aB}$ \\
$20-30^{\circ} \mathrm{C}$ & $5,47 \mathrm{aA}$ & $4,66 \mathrm{aA}$ & $0,00 \mathrm{aB}$ & $1,05 \mathrm{aB}$ \\
$30^{\circ} \mathrm{C}$ & $5,67 \mathrm{aA}$ & $3,83 \mathrm{abB}$ & $0,04 \mathrm{aC}$ & $0,04 \mathrm{aC}$ \\
$40^{\circ} \mathrm{C}$ & $0,00--$ & $0,00--$ & $0,00--$ \\
\hline Valor "F" $\mathrm{p} /$ Temperatura & & & & $18,64^{* *}$ \\
Valor "F" p/ Qualidade de luz & & & & $167,24^{* *}$ \\
Valor "F" p/ Interação (T x Q) & & & $10,65^{* *}$ \\
$\mathrm{CV}(\%):$ & & & 26,80 \\
\hline
\end{tabular}

Letras iguais (minúsculas na coluna e maiúsculas na linha) não diferem entre si pelo teste de Tukey a 5\% de probabilidade. As temperaturas de $10^{\circ} \mathrm{C}$ e $40^{\circ} \mathrm{C}$ foram excluídas da análise estatística.

** Significativo ao nível de $1 \%$ de probabilidade $(\mathrm{p}<.01)$.

Fonte: Elaboração dos autores. 
O processo germinativo foi prejudicado pelo escuro e pela luz vermelho-distante, indicando caráter fotoblástico preferencialmente positivo (KLEIN; FELIPPE, 1991), o que pode ser resultado da atuação do fitocromo tipo "B" que, segundo Cardoso(2008), ao absorverluzna faixa do vermelhodistante converte-se na forma inativa impedindo o processo germinativo, e o oposto acontece ao absorver o vermelho. Marcos Filho (2005) refere-se a esta fotodormência como uma estratégia ecológica para a manutenção da viabilidade das sementes no banco do solo, já que a luz vermelho-distante atinge maiores profundidades, o que leva as sementes a permanecerem com o fitocromo na forma inativa. Um meio de utilizar a inativação do fitocromo como uma estratégia de manejo para as sementes de plantas daninhas presentes na superfície do solo seria o uso de cobertura morta que agiria de modo a filtrar a radiação luminosa chegando ao solo maiores quantidades de luz vermelho-distante impedindo a germinação e consequentemente o processo de infestação de E. coccinea e outras de semelhante comportamento (CARVALHO; NAKAGAWA, 2012).

Nas temperaturas de $30{ }^{\circ} \mathrm{C}$ constante e $20-$ $30^{\circ} \mathrm{C}$ alternadas a porcentagem de germinação foi superior para a luz branca, indicando que esta condição luminosa foi mais eficiente para ativar o fitocromo que a luz vermelha isolada, levando em consideração os pressupostos fisiológicos de que só há germinação se o fitocromo estiver na forma ativa. Isto é explicado pelo fato da luz branca ser o resultado da junção de todos os feixes luminosos, promovendo maior energia para as reações, e mesmo havendo quantidade praticamente igual de vermelho e vermelho-distante as sementes permanecem predominantemente com o fitocromo na forma ativa, garantindo o andamento do processo germinativo (NULTSCH, 2000).
As temperaturas de 10 e $40^{\circ} \mathrm{C}$ inibiram completamente a germinação das sementes de $E$. coccinea para qualquer qualidade de luz (Tabela 1), indicando que as mesmas ultrapassam as chamadas temperaturas cardeais, mínima e máxima, desta espécie.

\section{Armazenamento e qualidade de Luz}

As sementes recém-colhidas apresentaram um comportamento fotoblástico preferencialmente positivo (como já verificado no ensaio 1), no entanto, observa-se nas figuras 1 e 2 que o armazenamento do aquênio acarretou em mudanças na fotossensibilidade do processo germinativo, revelando uma perda gradual da fotodormência ocasionada pelo vermelho-distante e escuro. De acordo com a figura 1 , sob luz branca a germinação máxima estimada $(96,2 \%)$ de E. coccinea ocorreu aos 5,7 meses de armazenamento, praticamente sem variação ao longo dos períodos. Já sob luz vermelha seu máximo potencial de germinação (91,5\%) foi aos 7,4 meses, o que representa um acréscimo de 43,4\% em comparação à porcentagem de germinação das sementes recém colhidas. Na luz vermelho-distante o valor máximo estimado foi de $83 \%$ aos 7,6 meses de armazenamento enquanto que no escuro a germinação máxima (68\%) só ocorreu aos 11 meses de armazenamento. É importante ressaltar que, diferentemente da luz branca ou vermelha, a germinação sob luz vermelho-distante ou escuro tenderam a zero quando as sementes não foram submetidas ao armazenamento. 
Figura 1. Porcentagem de germinação de sementes recém-colhidas e armazenadas de Emilia coccinea sobmetidas à diferentes qualidades de luz.

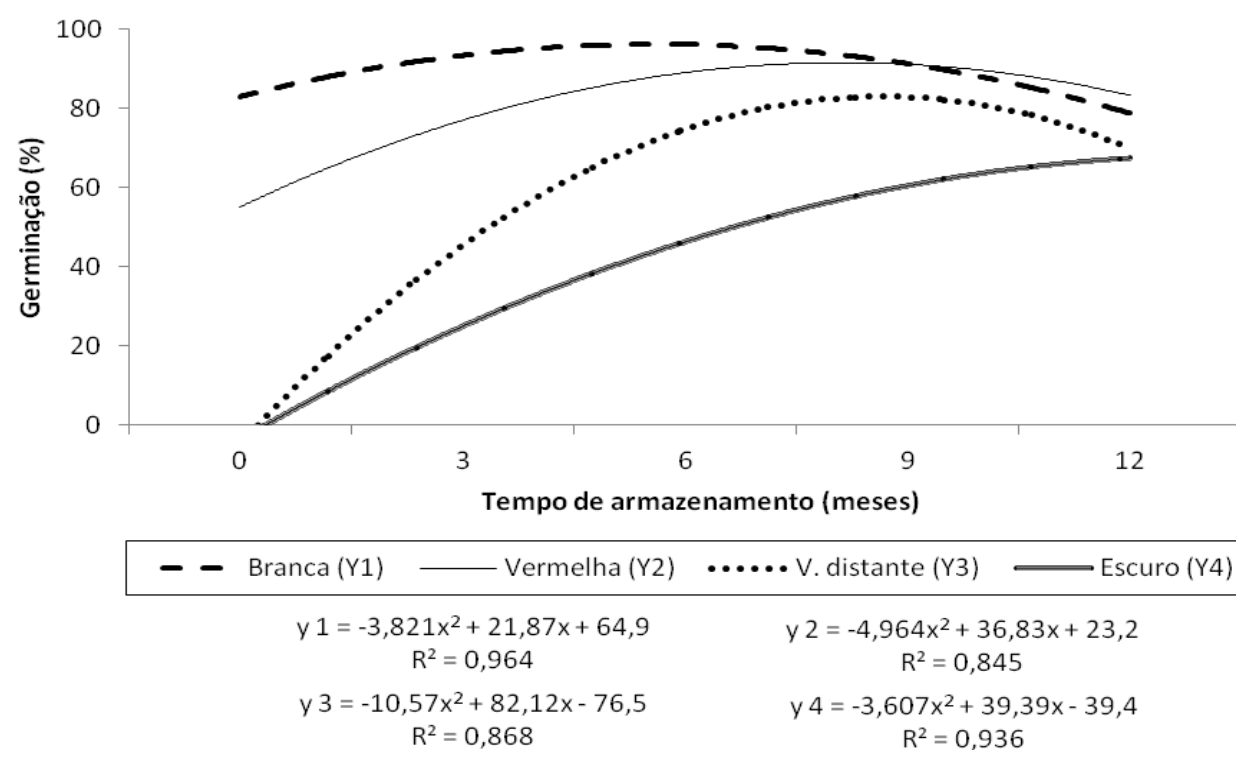

Fonte: Elaboração dos autores.

Figura 2. Índice de velocidade de germinação (IVG) de sementes recém-colhidas e armazenadas de Emilia coccinea sobmetidas a diferentes qualidades de luz.

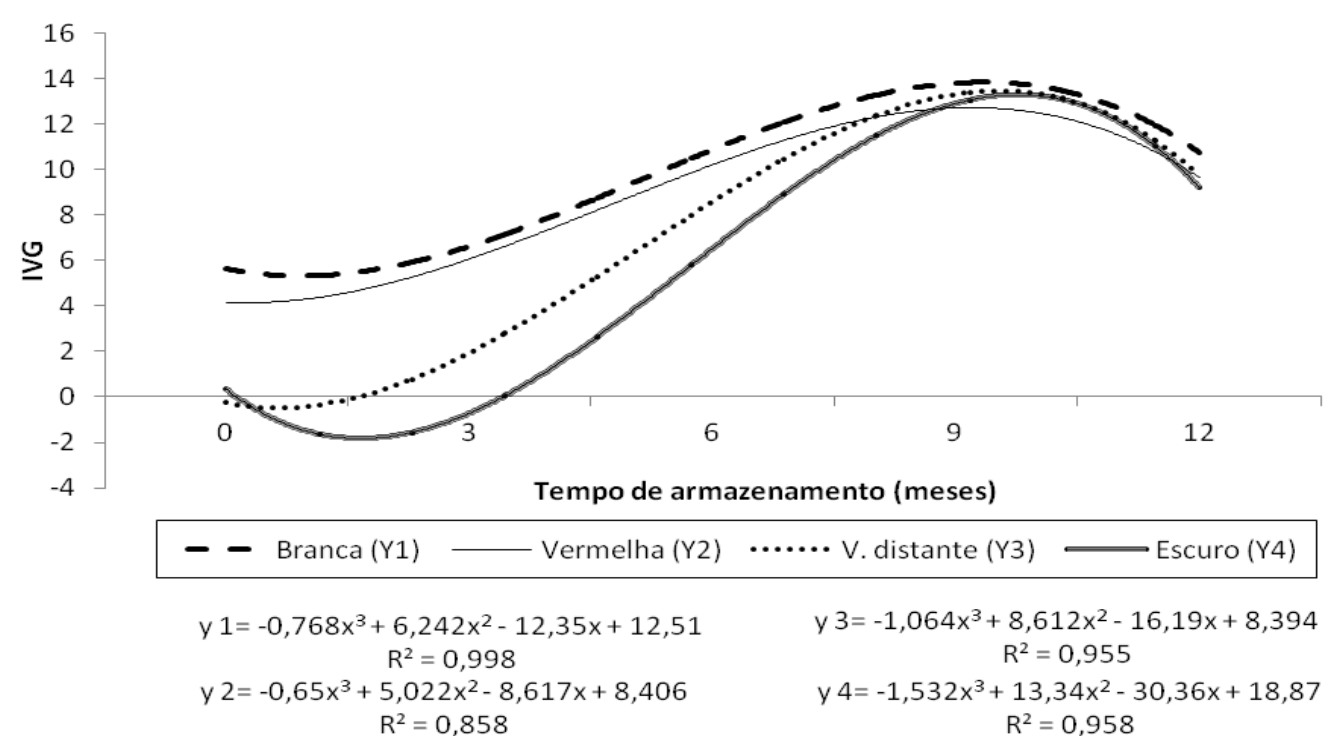

Fonte: Elaboração dos autores. 
Até os três meses de armazenamento a baixa germinação foi mantida para a luz vermelho-distante e para o escuro não havendo diferença estatística ( $p>0,05)$ para estas condições. O armazenamento por seis meses proporcionou a perda completa da fotodormência ocasionada pela luz vermelhodistante, e parte da dormência promovida pelo escuro (Tabelas 3 e 4). Pode-se considerar, com estes resultados, que para as sementes de E. coccinea o fitocromo tipo B pré-existente vai deixando de atuar no processo germinativo quando as sementes atingem seis meses após a maturação. A inibição da germinação pelo escuro só foi completamente inibida entre seis e nove meses de armazenamento, sendo o processo da germinação desta espécie, a partir deste momento, controlado pelo fitocromo tipo A, que segundo Takaki (2001) é o tipo de fitocromo que atua nas sementes classificadas como fotoblásticas neutras. Estes resultados corroboram o relato de Marcos Filho (2005) ao mencionar que a influência da luz diminui com o envelhecimento da semente, revelando uma alternativa natural de sobrevivência, tendo em vista, que com o passar do tempo o fenômeno da deterioração é irreversível e inevitável (CARVALHO; NAKAGAWA, 2012), portanto, a semente vai se tornando menos exigente a essa condição ambiental para poder garantir a perpetuação da espécie.

Na luz branca a porcentagem de germinação se manteve praticamente constante independente da idade dos aquênios, dentro de um período de um ano, com acréscimo no índice de velocidade quando ultrapassaram os seis meses de armazenamento (Figuras 1 e 2). Resultado divergente foi encontrado por Gomes e Fernandes (2002) estudando a germinação dos aquênios de Baccharis dracunculifolia, outra espécie considerada invasora e também da família Asteraceae, onde a porcentagem de germinação foi 70 vezes superior para os aquênios recém-colhidos em comparação aos armazenados por um ano. Isto indica que a viabilidade das sementes perante o armazenamento ocorre de maneira específica, não havendo a possibilidade de generalização de comportamento, mesmo para espécies de mesma família botânica.

Tabela 3. Germinação de sementes recém-colhidas e armazenadas de Emilia coccinea sob diferentes qualidades de luz.

\begin{tabular}{lrrrr}
\hline \multicolumn{4}{c}{ GERMINAÇÃO (\%) } \\
\hline Períodos de Armazenamento & \multicolumn{4}{c}{ Qualidades de luz } \\
\hline & Branca & Vermelha & Verm. Distante & Escuro \\
\cline { 2 - 5 } Recém-colhida & $82,0 \mathrm{~A}$ & $51,5 \mathrm{~A}$ & $1,5 \mathrm{~B}$ & $1,0 \mathrm{~B}$ \\
3 meses & $95,5 \mathrm{~A}$ & $86,5 \mathrm{~A}$ & $26,5 \mathrm{~B}$ & $16,0 \mathrm{~B}$ \\
6 meses & $95,5 \mathrm{~A}$ & $82,0 \mathrm{~A}$ & $93,0 \mathrm{~A}$ & $45,5 \mathrm{~B}$ \\
9 meses & $90,0 \mathrm{~A}$ & $91,0 \mathrm{~A}$ & $77,5 \mathrm{~A}$ & $88,5 \mathrm{~A}$ \\
12 meses & $79,5 \mathrm{~A}$ & $84,5 \mathrm{~A}$ & $87,5 \mathrm{~A}$ & $76,5 \mathrm{~A}$ \\
\hline Valor "F" p/ Qualidade de Luz & & & $32,57^{* *}$ \\
Valor "F" p/ Tempo de Armaz. & & & & $39,43^{* *}$ \\
Valor "F" p/ Interação (Q x T) & & & & $09,54^{* *}$ \\
CV a (\%): & & & 20,45 \\
CV b (\%): & & & 18,43 \\
\hline
\end{tabular}

Letras iguais na linha não diferem entre si pelo teste de Tukey a 5\% de probabilidade.

** Significativo ao nível de $1 \%$ de probabilidade $(\mathrm{p}<.01)$.

Fonte: Elaboração dos autores. 
Tabela 4. Índice de velocidade de germinação (IVG) de sementes recém-colhidas e armazenadas de Emilia coccinea sob diferentes qualidades de luz.

\begin{tabular}{lrrrr}
\hline & \multicolumn{4}{c}{ IVG } \\
\hline Períodos de Armazenamento & & \multicolumn{3}{c}{ Qualidades de luz } \\
\hline & Branca & Vermelha & Verm. Distante & Escuro \\
\cline { 2 - 5 } Recém-colhida & $5,67 \mathrm{~A}$ & $3,83 \mathrm{~A}$ & $0,04 \mathrm{~B}$ & $0,04 \mathrm{~B}$ \\
3 meses & $6,52 \mathrm{~A}$ & $7,39 \mathrm{~A}$ & $0,78 \mathrm{~B}$ & $0,44 \mathrm{~B}$ \\
6 meses & $11,05 \mathrm{~A}$ & $8,22 \mathrm{~A}$ & $10,34 \mathrm{~A}$ & $4,81 \mathrm{~B}$ \\
9 meses & $13,69 \mathrm{~A}$ & $14,03 \mathrm{~A}$ & $12,15 \mathrm{~A}$ & $14,08 \mathrm{~A}$ \\
12 meses & $10,78 \mathrm{~A}$ & $9,31 \mathrm{~A}$ & $10,01 \mathrm{~A}$ & $8,91 \mathrm{~A}$ \\
\hline Valor "F" p/ Qualidade de Luz & & & $18,38^{* *}$ \\
Valor "F" p/ Tempo de Armaz. & & & $101,95^{* *}$ \\
Valor "F" p/ Interação (Q x T) & & & $4,75^{* *}$ \\
CV a (\%): & & & 24,19 \\
CV b (\%): & & & 23,57 \\
\hline
\end{tabular}

Letras iguais na linha não diferem entre si pelo teste de Tukey a 5\% de probabilidade.

** Significativo ao nível de $1 \%$ de probabilidade $(\mathrm{p}<.01)$.

Fonte: Elaboração dos autores.

Com relação à velocidade da germinação, esta aumentou seu índice com o envelhecimento das sementes até os nove meses de armazenamento, para todas as qualidades de luz avaliadas, com decréscimo da velocidade a partir deste período, como pode ser visto na figura 2. Estes resultados indicam que entre nove e doze meses de armazenamento as sementes de E. coccinea começam a perder o vigor, mostrando que sementes desta espécie podem permanecer no banco do solo por um período aproximado de dez meses (Figura 2) sem haver decréscimo algum na sua viabilidade ou potencial para infestação.

\section{Profundidade de semeadura}

Sementes que se encontravam na superfície do substrato garantiram alta porcentagem de emergência, havendo um decréscimo acentuado com o aprofundamento das mesmas, como pode ser visto nas figuras 3 e 5 . As sementes começaram a emergir a partir do sétimo dia após a semeadura independente da profundidade em que se encontravam (Figura 5), mas o IVE foi negativamente afetado com o enterrio das sementes no substrato (Figura 4).

A porcentagem de emergência passou de $90 \%$ para as sementes que se encontravam na superfície do substrato para $70 \%$ com o aprofundamento em um $\mathrm{cm}$. Sementes que estavam a dois $\mathrm{cm}$ abaixo da superfície do substrato apresentaram pouca emergência de plântulas, aproximadamente $30 \%$. Marcos Filho (2005) relata que as radiações vermelhas podem penetrar no solo no máximo até 2,5 $\mathrm{cm}$, enquanto as infravermelhas (vermelho-distante) atingem maior profundidade no solo, portanto a semeadura mais profunda poderia expor as sementes apenas a radiações prejudiciais à germinação. Há também o fato de que estas profundidades possam ter representado impedimento físico imposto pelo substrato, e que por se tratar de sementes muito pequenas, apresentem nos cotilédones, reservas insuficientes para emergir em maiores profundidades (CANOSSA et al., 2007). Isto explicaria a inibição total da emergência das plântulas na profundidade de três cm. Pode-se inferir, então, que nesta profundidade a semente já encontra-se armazenada no solo compondo o banco de sementes.

Com este conhecimento, então, pode-se dizer que técnicas de agricultura baseadas em plantio direto ou de cultivo mínimo do solo seriam mais eficientes para impedir o estabelecimento de E. coccinea. Sem o revolvimento do solo, sementes que se encontram no banco do solo não seriam levadas à superfície, impossibilitando o processo germinativo. 
Figura 3. Emergência de plântulas de Emilia coccinea submetidas a diferentes profundidades de semeadura.

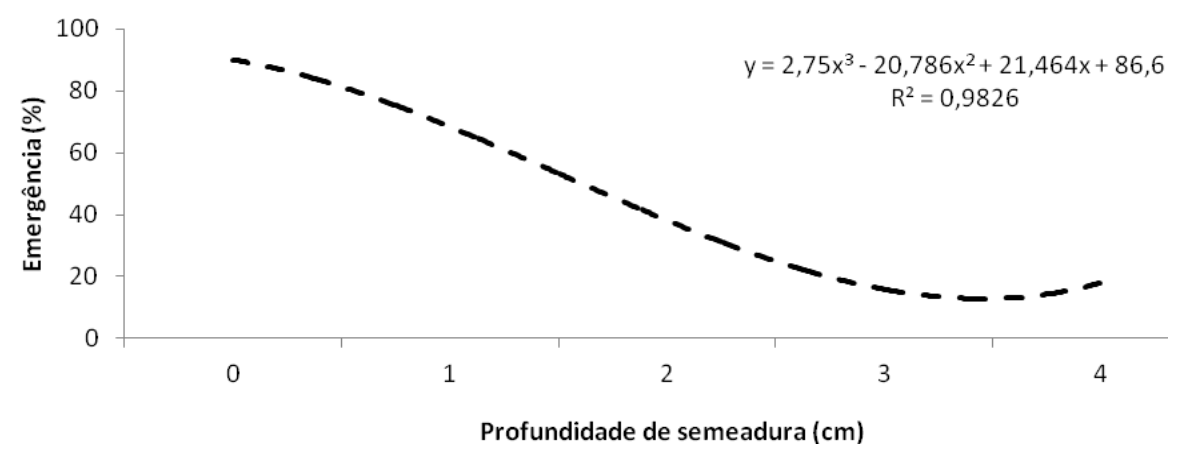

Fonte: Elaboração dos autores.

Figura 4. Índice de velocidade de emergência (IVE) de plântulas de Emilia coccinea submetidas a diferentes profundidades de semeadura.

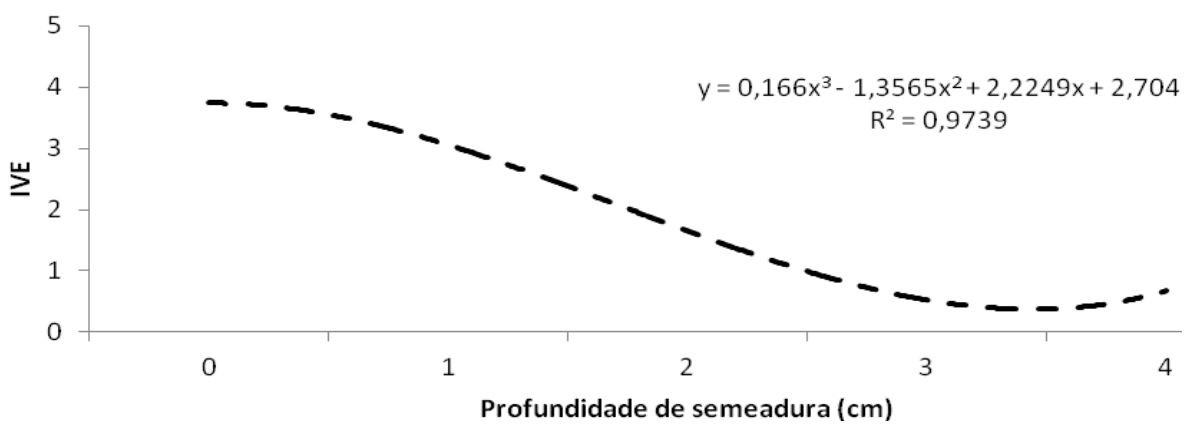

Fonte: Elaboração dos autores.

Figura 5. Emergência de plântulas de Emilia coccinea submetidas a diferentes profundidades de semeadura em função dos dias decorridos após a semeadura.

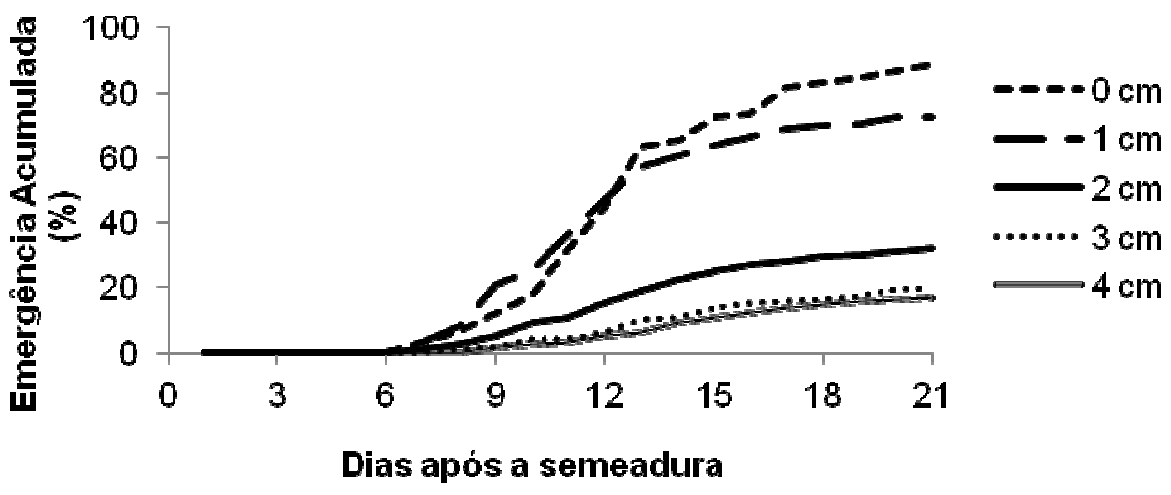

Fonte: Elaboração dos autores. 


\section{Conclusões}

O processo germinativo de sementes recémcolhidas de E. coccinea ocorre de maneira mais eficiente em temperatura de $30^{\circ} \mathrm{C}$ ou alternada de $20-30^{\circ} \mathrm{C}$ sob luz branca.

O armazenamento dos aquênios por nove meses promove a perda completa da fotodormência ocasionada pelo escuro e pela luz vermelho-distante.

A capacidade de emergência das plântulas é superior quando as sementes encontram-se na superfície do substrato.

\section{Referências}

AGRA, M. F.; SILVA, K. N.; BASÍLIO, I. J. L. D.; FREITAS, P. F.; BARBOSA-FILHO, J. M. Survey of medicinal plants used in the region Northeast of Brazil. Revista Brasileira de Farmacognosia, Curitiba, v. 18, n. 3, p. 472-508, 2008.

ALMEIDA, M. L.; MUNDSTOCK, C. M. A qualidade da luz afeta o afilhamento em plantas de trigo, quando cultivadas sobre competição. Ciência Rural, Santa Maria, v. 31, n. 3, p. 401-408, 2001.

CANOSSA, R. S.; OLIVEIRA JÚNIOR, R. S.; CONSTANTIN, J.; BIFFE, D. F.; ALONSO, D. G.; FRANCHINI, L. H. M. Profundidade de semeadura afetando a emergência de plântulas de Alternanthera tenella. Planta Daninha, Viçosa, MG, v. 25, n. 4, p. 719725, 2007.

CANOSSA, R. S.; OLIVEIRA JÚNIOR, R. S.; CONSTANTIN, J.; BRACCINI, A. L.; BIFFE, D. F.; ALONSO, D. G.; BLAINSKI, E. Temperatura e luz na germinação das sementes de apaga-fogo (Alternanthera tenella). Planta Daninha, Viçosa, MG, v. 26, n. 4, p. 745$750,2008$.

CARDOSO, V. J. M. Germinação. In: KERBAUY, G. B. Fisiologia vegetal. 2. ed. Rio de Janeiro: Guanabara Koogan S.A, 2008. p. 384-408.

CARVALHO, N. M.; NAKAGAWA, J. Sementes: ciência, tecnologia e produção. 5. ed. Jaboticabal: FUNEP, 2012. 590 p.

CORRÊIA JÚNIOR, C.; SCHEFFER, M. C.; MING, L. C. Cultivo agroecológico de plantas medicinais, aromáticas e condimentares. Curitiba: EMATER, 2006. $75 \mathrm{p}$.
DIAS-FILHO, M. B. Alguns aspectos da ecologia de sementes de duas espécies de plantas invasoras da Amazônia brasileira: implicações para o recrutamento de plântulas em áreas manejadas. In: GASCON, C.; MOUTINHO, P. (Ed.). Floresta amazônica: dinâmica, regeneração e manejo. Manaus: INPA, 1998. p. 233-248.

EMPRESA BRASILEIRA DE PESQUISA AGROPECUÁRIA - EMBRAPA. Centro Nacional de Pesquisa de Solos. Sistema brasileiro de classificação de solos. Rio de Janeiro: Embrapa, 2006.

FLOSS, E. L. Fisiologia das plantas cultivadas: o estudo do que está por trás do que se vê. 4. ed. rev. Passo Fundo: UPF: Ed. da Universidade de Passo Fundo, 2008. 733 p.

GOMES, V.; FERNANDES, G. W. Germinação de aquênios de Baccharis dracunculifolia D. C. (Asteraceae). Acta Botânica Brasilica, Feira de Santana, v. 16, n. 4, p. 421-427, 2002.

INSTITUTO NACIONAL DE METEOROLOGIA - INMET. Ministério da agricultura, pecuária e abastecimento. Gráficos climatológicos: capitais do nordeste. Brasília: INMET, 2013. Disponível em: $<$ http://www.inmet.gov.br/portal/index.php?r=clima/ graficosClimaticos $>$. Acesso em: 15 jun. 2013.

KENDRICK, R. E.; FRANKLAND, B. Fitocromo e crescimento Vegetal. São Paulo: EPU: Ed. da Universidade de São Paulo, 1981. 76 p.

KLEIN, A.; FELIPPE, G. M. Efeito da luz na germinação de sementes de ervas invasoras. Pesquisa Agropecuária Brasileira, Brasília, v. 26, n. 7, p. 955-966, 1991.

LORENZI, H. Manual de identificação e controle de plantas daninhas: plantio direto e convencional. 6. ed. Nova Odessa: Instituto Plantarium, 2006. 339 p.

LORENZI, H. Plantas daninhas do Brasil: terrestres, aquáticas, parasitas e tóxicas. 4. ed. Nova Odessa: Instituto Plantarum, 2008. 640 p.

MAGUIRE, J. D. Speed of germination-aid in selection and evaluation for seedling emergence and vigor. Crop Science, Madison, v. 2, n. 1, p. 176-177, 1962.

MARCOS FILHO, J. Fisiologia de sementes de plantas cultivadas. Piracicaba: FEALQ, 2005. 495 p.

NASSIF, S. M. L.; VIEIRA, I. G.; FERNANDES, G. D. Fatores externos que influenciam na germinação de sementes. Informativo Sementes IPEF, Piracicaba, abr. 1998. Disponível em: <http://www.ipef.br/tecsementes/ germinacao.asp > . Acesso em: 15 jun. 2013.

NOUMI, E.; DIBAKTO, T. W. Medicinal plants used for peptic ulcer in the Bangangte region, western Cameroon. Fitoterapia, Philadelphia, v. 71, n. 4, p. 406-412, 2000. 
NULTSCH, W. Botânica geral. 10. ed. rev. atual. Porto Alegre: Artmed, 2000. 489 p.

ROBERTS, E. H. A search for patten and form. Seed Science Research, Cambridge, v. 9, n. 1, p. 181-208, 1999.

TAKAKI, M. New proposal of classification of seeds based on forms of phitochome instead of photoblastism. Revista Brasileira de Fisiologia Vegetal, Rio Claro, v. 13, n. 1, p. 104-108, 2001.

TEKE, G. N.; KUIATE, J. R.; NGOUATEU, O. B.; GATSING, G. Antidiarrhoeal and antimicrobial activities of Emilia coccinea (Sims) G. Don extracts. Journal of Ethnopharmacology, Philadelphia, v. 112, n. 2, p. 278283, 2007.
VIDAL, R. A.; KALSING, A.; GOULART, I. C. G. R.; LAMEGO, F. P.; CHRISTOFFOLETI, P. J. Impacto da temperatura, irradiância e profundidade das sementes na emergência e germinação de Conyza bonariensis e Conyza canadensis resistentes ao glyphosate. Planta Daninha, Viçosa, MG, v. 25, n. 2, p. 309-315, 2007.

VIVIAN, R.; GOMES JÚNIOR, F. G.; CHAMMA, H. M. C. P.; SILVA, A. A.; FAGAN, E. B.; RUIZ, S. T. Efeito da luz e da temperatura na germinação de Alternathera tenella, Conyza bonariensis e Digitaria ciliaris. Planta Daninha, Viçosa, MG, v. 26, n. 3, p. 507-513, 2008.

YAMASHITA, O. M.; GUIMARÃES, S. C.; SILVA, J. L.; CARVAlHO, M. A. C.; CAMARGO, M. F. Fatores ambientais sobre a germinação de Emilia sonchifolia. Planta Daninha, Viçosa, MG, v. 27, n. 4, p. 673-681, 2009. 